\title{
TRABALHO NOTURNO COMO FATOR DE RISCO NA CARCINOGÊNESE ${ }^{1}$
}

\author{
NIGHT WORK AS A RISK FACTOR IN CARCINOGENESIS
}

\section{EL TRABAJO NOCTURNO COMO UN FACTOR DE RIESGO EN LA CARCINOGÉNESIS}

\author{
Marina IZU* \\ Elaine Antunes CorTez ${ }^{* *}$ \\ Geilsa CaValcanti Valente ${ }^{* * *}$ \\ ZENITH Rosa SILVINO ${ }^{* * *}$
}

\begin{abstract}
RESUMO
Objetivos: identificar os efeitos da desregulação do ritmo circadiano no organismo humano do trabalhador noturno; descrever a produção científica sobre o trabalho noturno como fator de risco na carcinogênese. Método: Trata-se de um estudo descritivo e exploratório com abordagem qualitativa, bibliográfico, onde os dados foram coletados da Biblioteca Virtual da Saúde (BVS), Medline, LILACS, SciELO. A coleta de dados realizou-se no período de fevereiro-abril de 2009 e após a coleta dos dados foi realizada a pré-leitura, leitura seletiva seguida de leitura interpretativa. Destaca-se que foi constatada a inexistência de estudos brasileiros no tema proposto. Por este motivo optou-se por estudos internacionais, escritos na língua inglesa, onde foram selecionadas como referência 10 estudos, dos quais emergiram duas categorias temáticas: Trabalho Noturno: Fator de risco e Efeitos da desregulação do ritmo circadiano: Trabalhador Noturno e Câncer. Resultado: o trabalho noturno pode ser um fator de risco no aparecimento de câncer de mama, endometrial, de cólon, demonstrado através de estudos epidemiológicos. Além disso, a alteração do ritmo circadiano pela exposição à luz durante a noite pode ser um fator para várias doenças como as gástricas, cardiovascular, desordens no sono e câncer. A desregulação do ritmo circadiano pode alterar a delicada balança entre os fatores promotores e inibidores da divisão celular. Conclusão: o trabalhado noturno pode levar o aparecimento de várias doenças devido à desregulação do ritmo circadiano. Sendo assim, o enfermeiro do trabalho pode contribuir na elaboração de escalas de trabalho que levem em consideração os trabalhadores mais adaptados para o turno, visando minimizar os danos a saúde.
\end{abstract}

Palavras chave: Trabalho noturno, câncer, ritmo circadiano.

\begin{abstract}
Objectives: To identify the deregulation effects of the human body's circadian rhythms in night shift workers, as described by the scientific literature regarding night shift as a risk factor in carcinogenesis. Methods: A

\footnotetext{
${ }^{1}$ Monografia (Pós-Graduação em Enfermagem do Trabalho). 2009. Centro Universitário Plínio Leite - UNIPLI, Niterói RJ. Brasil.

* Enfermeira, especialista em Enfermagem do Trabalho, UNIPLI, Niterói, Rio Janeiro, Brasil. Email: izu.marina@gmail.com ${ }^{* *}$ Doutora em Enfermagem, professora adjunto do Departamento de Enfermagem Materno-Infantil e Psiquiatria da Escola de Enfermagem Aurora de Afonso Costa, Universidade Federal Fluminense, Brasil.

${ }^{* *}$ Enfermeira, professora adjunto do Departamento de Fundamentos e Administração em Enfermagem da Escola de Enfermagem Aurora de Afonso Costa, Universidade Federal Fluminense, Brasil.

${ }^{* * * *}$ Enfermeira, professora titular do Departamento de Fundamentos e Administração em Enfermagem da Escola de Enfermagem Aurora de Afonso Costa, Universidade Federal Fluminense, Brasil.
} 
descriptive study with qualitative and bibliographic approach was performed. Data were collected from the Virtual Health Library (VHL), Medline, LILACS, SciELO. Data collection took place during February, March and April 2009 and after data collection, a pre-reading, selective reading followed by an interpretive reading was performed It should be noted that a lack of Brazilian studies on the subject was found. For this reason we chose ten international studies, written in English, which were selected as reference; From them two studies emerge: Night Shift: Risk factor and The effects of deregulation of the circadian rhythm: night shift and cancer. Result: Night Shift may be a risk factor for the occurrence of endometrial, colon, breast cancer, demonstrated by epidemiological studies. In addition, changes in the circadian rhythm of light exposure at night may be a factor in many diseases such as gastric, cardiovascular, sleep disorders and cancer. The deregulation of circadian rhythms can disrupt the delicate balance between factors that promote cell division and inhibition. Conclusion: the night shift can cause the appearance of various diseases due to deregulation of the circadian rhythm. Thus, the work of the nurse can help in the development of work schedules that take into account workers adaptation to the shift, to minimize damage to health.

Key words: Night work, cancer, circadian rhythm.

\section{RESUMEN}

Objetivos: Identificar los efectos de la desregulación de los ritmos circadianos del cuerpo humano a los trabajadores del turno de noche, que describe la literatura científica sobre el trabajo nocturno como un factor de riesgo en la carcinogénesis. Método: Se realizó un estudio descriptivo con enfoque cualitativo, bibliográfico, se recolectaron datos de la Biblioteca Virtual en Salud (BVS), Medline, LILACS, SciELO. La recolección de datos tuvo lugar durante febrero-abril de 2009 y después de la recolección de datos se realizó la pre-lectura, lectura selectiva seguida de una lectura interpretativa. Cabe señalar que se constató la falta de estudios brasileños sobre el tema. Por esta razón se optó por los estudios internacionales, escritos en inglés, donde fueron seleccionados como referencia 10 estudios, de los que emergen dos temas: el trabajo nocturno: factor de riesgo y los efectos de la desregulación del ritmo circadiano: el trabajo nocturno y el cáncer. Resultado: el trabajo nocturno puede ser un factor de riesgo para la aparición de cáncer de mama, endometrio, colon, demostrada por estudios epidemiológicos. Además, los cambios en el ritmo circadiano de exposición a la luz en la noche puede ser un factor de muchas enfermedades tales como gástricas, cardiovasculares, trastornos del sueño y cáncer. La desregulación de los ritmos circadianos puede alterar el delicado equilibrio entre los factores que promueven la división celular y la inhibición. Conclusión: el turno de noche puede provocar la aparición de diversas enfermedades debido a la desregulación del ritmo circadiano. Así, el trabajo de la enfermera puede ayudar en el desarrollo de los horarios de trabajo que tengan en cuenta a los trabajadores para adaptarse a la pieza, para minimizar el daño a la salud.

Palabras clave: Trabajo nocturno, cáncer, ritmo circadiano.

Fecha recepción: 06/04/10 Fecha aceptación: 15/10/11

\section{INTRODUÇÃO}

Algumas profissões, principalmente na área da saúde, funcionam vinte e quatro (24) horas para atender a demanda de serviços, levando a dessincronização entre o ciclo vigília- sono e outros ritmos biológicos. O ciclo vigília-sono é um ritmo biológico de caráter endógeno, que é determinado geneticamente e por pistas temporais (1).

Toda vez que a atividade laboral exigir trabalho em turnos, diurno e noturno, não importando que seja feito em turnos alternantes ou fixos, os trabalhadores estarão sempre sujeitos a uma dessincronização e submetidos a um maior risco de apresentarem uma série de distúrbios de ordem fisiológica e psicossocial (2).

Desta forma, a pesquisa tem como objeto 
os efeitos da desregulação do ritmo circadiano no organismo humano do trabalhador noturno como um fator de risco na carcinogênese.

O termo ritmo circadiano provém do latim circa diem, que significa "por volta de um dia”. As funções orgânicas humanas seguem um padrão ao longo de vinte e quatro (24) horas do dia, denominado ritmo circadiano, e essas funções são controladas pelo relógio biológico localizado no cérebro (núcleo supraquiasmático), regulador do hipotálamo, que controla o funcionamento das glândulas endócrinas secretoras de hormônios essenciais ao funcionamento do organismo (3).

Os ritmos biológicos também são influenciados por sincronizadores externos, sendo o fenômeno claro-escuro o mais potente deles para os seres vivos. Além disso, para o homem, outro sincronizador é o social, que estabelece o período noturno como horário de repouso. O ciclo claro-escuro é o mais importante fator ambiental sincronizador dos ritmos biológicos. A luz muda a fase do relógio circadiano por uma cascata de eventos no interior das células do núcleo supraquiasmático (NSQ), incluindo a ativação do gene Per1. A informação da claridade/escuridão é transmitida, via trato retino-hipotalâmico, da retina (único receptor da informação) para o núcleo supraquiasmático (NSQ) e deste para a glândula pineal, que regula a secreção de melatonina (4).

Ressalta-se que a melatonina exerce um efeito de sincronização no marcador circadiano, sendo fortemente suprimida na presença de luz, aumentando até um determinado platô durante o sono e diminuindo novamente com o despertar. A melatonina é uma indolamina produzida pela glândula pineal, que se localiza no teto do terceiro entre os dois hemisférios cerebrais e sua secreção está relacionada ao ciclo claro-escuro, sendo o pico de secreção no meio da noite. É um órgão endócrino ativo, conectado à retina pelas projeções retino-hipotalâmicas via núcleo supraquiasmático do hipotálamo, no qual funciona como um controle autônomo para o gânglio cervical superior, de onde as fibras ganglionares posteriores alcançam a pineal. Há outras fontes de produção da melatonina, como a retina, corpo ciliar da íris, glândulas harderianas e lacrimais, porém estas fontes teriam contribuição mínima para a concentração plasmática da melatonina (5).

Além disso, a melatonina influencia o ritmo de vários outros processos fisiológicos durante a noite como a digestão, que se torna mais lenta; a temperatura corporal cai; o ritmo cardíaco e a pressão diminuem e o sistema imunológico é estimulado. É um poderoso antioxidante e atua na regulação do estado vigília-sono, e participa do controle do relógio biológico (5).

A melatonina parece aumentar a mobilidade e a atividade das células de defesa, estimulação da formação dos anticorpos e facilitar a defesa contra microrganismos. Por este motivo, é considerada a molécula chave que controla o ciclo circadiano dos animais e humanos. Evidencia-se também que a melatonina pode influenciar os processos fisiológicos e neoplásicos do sistema reprodutor.

A resposta para o ciclo natural da luz resulta em uma organização temporal adaptativa nos humanos e outros animais. Com a invenção e o uso da luz elétrica, esta organização temporal tem sido dramaticamente alterada. A luz a noite tem significado social, ecológico, comportamental e consequências na saúde que somente agora começaram a aparecer (6).

A exposição à luz a noite atrapalha o ritmo circadiano com alteração no padrão da atividade do sono, supressão na produção da melatonina, e desregulação dos genes envolvidos no aparecimento de câncer. Desta forma, evidencia-se que o trabalho noturno leva a exposição à noite à luz, resultando em repetida e freqüente rompimento do ritmo circadiano.

Muitas pesquisas têm sido desenvolvidas para explicar o aparecimento do câncer, porém ainda não há dados para que se saiba o 
motivo pela quais certos indivíduos adoecem ou tenham um risco maior para adoecer do que outros. Foi estabelecido que o aparecimento do câncer estivesse relacionado a uma multiplicidade de causas como a suscetibilidade e os fatores ou as condições resultantes do modo de vida e do ambiente (7).

A carcinogênese refere-se ao desenvolvimento de tumores malignos. O processo de carcinogênese, em geral se dá lentamente, podendo levar vários anos para que uma célula cancerosa prolifere e dê origem a um tumor visível. Esse processo passa por vários estágios antes de chegar ao tumor (7).

A legislação trabalhista brasileira prevê uma remuneração ao trabalhador noturno a título de indenização, o adicional noturno, porém não há outras políticas que minimizem os riscos a saúde do trabalhador.

Os objetivos propostos foram: identificar os efeitos da desregulação do ritmo circadiano no organismo humano do trabalhador noturno; descrever a produção científica sobre o trabalho noturno como fator de risco na carcinogênese.

\section{MÉTODO}

De acordo com os objetivos esta pesquisa constitui-se de um estudo descritivo e exploratório. $\mathrm{O}$ estudo descritivo tem como objetivo descrever as características de uma população ou fenômeno (carcinogêse no trabalho noturno), ou estabelecer relação entre variáveis. Alguns trabalhos descritivos vão mais além do que identificar a relação entre as variáveis, eles determinam o porquê dessa relação. As pesquisas descritivas servem para proporcionar uma nova visão de um problema (8).

A pesquisa exploratória tende tornar o problema mais explícito ou construir hipóteses. Ela objetiva o aprimoramento de idéias e a descoberta de intuições. Na maioria dos casos, o trabalho envolve levantamento bi- bliográfico, relatos de pessoa que tiveram a experiência prática e análise de exemplos. Freqüentemente essas duas pesquisas (descritiva e exploratória) são associadas quando os pesquisadores estão preocupados com a atuação prática.

A pesquisa qualitativa (9) é preocupada com o processo social e traz como contribuição para o trabalho, uma mesclagem entre as interpretações racionais e intuitivas sobre um assunto, permitindo uma melhor compreensão do fenômeno.

O tipo de estudo de acordo com o procedimento técnico/ instrumento foi a pesquisa bibliográfica desenvolvida com base no levantamento da produção científica já elaborada sobre o assunto até a atualidade.

A pesquisa bibliográfica propõe uma visão de diferentes pontos de um mesmo problema, através da análise de diversas fontes bibliográficas que podem incluir livros, impressos diversos e publicações periódicas (jornais e revistas). Ela possibilita ao pesquisador uma cobertura maior dos acontecimentos sobre o assunto sem ser necessário à busca direta dos dados (8). Os dados foram coletados entre os meses de fevereiro a abril de 2009.

A bibliografia potencial incluiu artigos científicos, teses, dissertações e editoriais publicados entre os anos de 1998 e 2008, pesquisados na Biblioteca Virtual de Saúde nas bases de dados LILACS, MEDLINE e SciELO, disponível no site da BIREME, através dos descritores: trabalho noturno; câncer, ritmo circadiano.

A quantidade de trabalhos encontrados está representada no Tabela 1 .

Devido ao quantitativo encontrado, foi necessário um refino na pesquisa, sendo feito nova busca utilizando descritores associados, conforme o Tabela dois (2).

Utilizou-se o formulário avançado, onde na primeira linha digitou-se o descritor de assunto "trabalho noturno", na segunda o descritor de assunto "câncer" e na terceira o descritor "ritmo circadiano" usando o ope- 
Tabela 1. Distribuição quantitativa das bibliografias encontradas nas bases de dados LILACS, SciELO, e MEDLINE.

\begin{tabular}{|l|r|r|r|r|}
\hline & \multicolumn{3}{|c|}{ Banco de Dados } & \\
\cline { 2 - 4 } DESCRITORES & LILACS & SciELO & MEDLINE & TOTAL \\
\hline Trabalho noturno & 154 & 64 & 1197 & 1415 \\
\hline Câncer & 28.832 & 4257 & 734.664 & 753 \\
\hline Ritmo Circadiano & 347 & 50 & 5478 & 5875 \\
\hline
\end{tabular}

Tabela 2. Distribuição quantitativa das bibliografias encontradas nas bases de dados, LILACS, SCIELO, e MEDLINE, sobre os temas Trabalho noturno, Câncer e Ritmo circadiano.

\begin{tabular}{|l|r|r|r|r|}
\hline \multirow{2}{*}{ DESCRITORES } & \multicolumn{3}{|c|}{ Banco de Dados } & \multirow{2}{*}{ TOTAL } \\
\cline { 2 - 5 } & LILACS & MEDLINE & SciELO & 6 \\
\hline Trabalho noturno e câncer & 2 & 67 & 0 & 61 \\
\hline $\begin{array}{l}\text { Trabalho noturno e ritmo } \\
\text { circadiano }\end{array}$ & 17 & 44 & 0 & 13 \\
\hline $\begin{array}{l}\text { Trabalho noturno e câncer e } \\
\text { ritmo circadiano }\end{array}$ & 2 & 11 & 0 & 6 \\
\hline
\end{tabular}

rador "and". Na base Medline, os descritores utilizados foram "night work", "cancer" e "circadian rhythm".

No processo de leitura (10) as fases se sucederam uma após a outra, respeitando a ordem cronológica e lógica do pensamento reflexivo. Após a coleta de dados, foi realizada uma pré-leitura ou leitura inspecional, com a finalidade de escolher qual material interessava efetivamente.

Foi realizada uma prévia, que permitiu uma breve investigação e penetrar no âmago do assunto, permitindo discorrer com mais facilidade, seguida de leitura de todos os resumos encontrados nos bancos de dados associados, totalizando 143 publicações. Foram excluídos trabalhos que fazem relação entre o trabalho noturno com estresse, fadiga ou qualidade de vida, bem como textos que relacionam o hormônio melatonina e animais.
Elaborou-se então um novo quadro, onde os artigos repetidos foram excluídos. A bibliografia potencial da análise de dados está descrita a seguir e contém 10 artigos. Desta feita, os artigos foram lidos na integra, alguns diretamente da revista e outros foram impressos nos sites oficiais das revistas, sendo feito a tradução, pois os textos que tinham relação com o tema proposta estão em inglês.

Assim, realizou-se uma leitura interpretativa que visava, através de um processo analítico para desvelar seus sentidos possíveis estabelecendo: relações textuais, relações contextuais e relações intertextuais. E, finalmente, uma análise temática (11) com a qual foi possível destacar as categorias ou os eixos temáticos.

Desta forma, as categorias emergiram: a) Trabalho Noturno: Fator de risco e b) Efeitos da desregulação do ritmo circadiano: Trabalhador Noturno e Câncer. 


\section{RESULTADOS E DISCUSSÃO}

De acordo com as dez (10) bibliografias potenciais selecionadas, optou-se em realizar o tabela três (3) de forma a se tornar mais didático a visualização da bibliografia eleita. As bibliografias estão organizadas de acordo com o ano de publicação em ordem cres- cente, nome dos autores, título do trabalho, nome da revista na qual estão publicados.

Segue a descrição e discussão da primeira categoria temática, onde didaticamente organizamos da mesma maneira que no Tabela 3 (três), porém, no quadro Tabela(4) só estão destacados os artigos da primeira categoria e no Tabela cinco (5) os artigos da segunda categoria.

Tabela 3: Distribuição das bibliografias potenciais selecionadas.

\begin{tabular}{|l|l|l|l|}
\hline Haus, Smolensky & 2006 & $\begin{array}{l}\text { Biological clocks and shift work: } \\
\text { circadian dy sregulation and potential } \\
\text { long-term effects }\end{array}$ & Cancer Causes Control \\
\hline Stevens & 2006 & $\begin{array}{l}\text { Artificial lighting in the industrialized } \\
\text { world: circadian disruption and breast } \\
\text { cancer }\end{array}$ & Cancer Causes Control \\
\hline Hansen & 2006 & $\begin{array}{l}\text { Risk of breast cancer after night- and } \\
\text { shift work: current evidence and } \\
\text { ongoing studies in Denmark }\end{array}$ & Cancer Causes Control \\
\hline Kubo et al. & 2006 & $\begin{array}{l}\text { Prospective Cohort Study of the Risk } \\
\text { of Prostate Cancer among Rotating- } \\
\text { Shift Workers: Findings from the } \\
\text { Japan Collaborative Cohort Study }\end{array}$ & Cancer Causes Control \\
\hline $\begin{array}{l}\text { Viswanathan } \\
\text { al. }\end{array}$ & 2007 & $\begin{array}{l}\text { Night Shift Work and the Risk of } \\
\text { Endometrial Cancer }\end{array}$ & Cancer Research \\
\hline
\end{tabular}

Tabela 4: Distribuição das bibliografias potenciais selecionadas da categoria "Câncer e Trabalho Noturno: Fator de risco".

\begin{tabular}{|l|c|l|l|}
\hline \multicolumn{1}{|c|}{ Autor (es) } & Ano & \multicolumn{1}{c|}{ Título } & \multicolumn{1}{c|}{ Revista } \\
\hline Schernhammer et al. & 2001 & $\begin{array}{l}\text { Rotating Night Shifts and Risk of Breast Cancer in } \\
\text { Women Particip ating in the Nurses'Health Study }\end{array}$ & $\begin{array}{l}\text { Journal of the National Cancer } \\
\text { Institute }\end{array}$ \\
\hline Davis et al. & 2001 & $\begin{array}{l}\text { Night Shift Work, Light at Night, and Risk of } \\
\text { Breast Cancer }\end{array}$ & $\begin{array}{l}\text { Journal of the National Cancer } \\
\text { Institute }\end{array}$ \\
\hline Schernhammer et al. & 2003 & $\begin{array}{l}\text { Night-Shift Work and Risk of Colorectal Cancer in in } \\
\text { the Nurses' Health Study }\end{array}$ & $\begin{array}{l}\text { Journal of the National Cancer } \\
\text { Institute }\end{array}$ \\
\hline Hansen & 2006 & $\begin{array}{l}\text { Risk of breast cancer after night- and shift work: } \\
\text { current evidence and ongoing studies in Denmark }\end{array}$ & Cancer Causes Control \\
\hline Kubo et al. & 2006 & $\begin{array}{l}\text { Prospective Cohort Study of the Risk of Prostate } \\
\text { Cancer among Rotating-Shift Workers: Findings } \\
\text { from the Japan Collaborative Cohort Study }\end{array}$ & Cancer Causes Control \\
\hline Viswanathan et al. & 2007 & $\begin{array}{l}\text { Night Shift Work and the Risk of Endometrial } \\
\text { Cancer }\end{array}$ & Cancer Research \\
\hline
\end{tabular}


Tabela 5: Distribuição das bibliografias potenciais selecionadas da categoria "Efeitos da desregulação do ritmo circadiano: Trabalhador noturno".

\begin{tabular}{|l|r|l|l|}
\hline \multicolumn{1}{|c|}{ Autor (es) } & \multicolumn{1}{c|}{ Ano } & \multicolumn{1}{c|}{ Título } & Revista \\
\hline $\begin{array}{l}\text { Schernhammer } \\
\text { Schulmeister }\end{array}$ & 2004 & $\begin{array}{l}\text { Melatonin and cancer risk: does light at night } \\
\text { compromise phy siologic cancer protection by } \\
\text { lowering serum melatonin levels? }\end{array}$ & British Journal of Cancer \\
\hline Davis, Miric & 2006 & $\begin{array}{l}\text { Circadian disruption, shift work and the risk of } \\
\text { cancer: a summary of the evidence and studies in } \\
\text { Seattle }\end{array}$ & Cancer Causes Control \\
\hline Haus, Smolensky & 2006 & $\begin{array}{l}\text { iological clocks and shift work: circadian } \\
\text { dy sregulation and potential long-term effects }\end{array}$ & Cancer Causes Control \\
\hline Stevens & 2006 & $\begin{array}{l}\text { Artificial lighting in the industrialized world: circadian } \\
\text { disruption and breast cancer }\end{array}$ & Cancer Causes Control \\
\hline
\end{tabular}

\section{Câncer e Trabalho Noturno: Fator de risco}

Esta categoria engloba os artigos que evidenciam o trabalho noturno como fator de risco no aparecimento de câncer. Os seis (6) artigos selecionados foram localizados na base de dados do Medline, especificados de acordo com o Tabela quatro (4) abaixo.

Em estudo que se examinou a relação entre o câncer de mama e o trabalho em rodízio noturno em enfermeiras acompanhadas durante 10 anos (1988-1998) pelo Nurses' Health Study (12). A informação foi obtida em 1988 sobre o número total de anos durante os quais as enfermeiras trabalharam em rodízio a noite, pelo menos três noites por mês. De maio até junho de 1988, os autores documentaram a incidência de 2441 casos de câncer de mama. O modelo de regressão logístico foi usado para calcular o risco relativo (RR) e intervalo de confiança $95 \%$ (IC 95 $\%$ ) ajustado, para variáveis de confundimento e fatores de risco para câncer de mama.

$\mathrm{O}$ resultado observado foi um moderado aumento no risco para câncer de mama entre mulheres que trabalharam 1 a 14 anos $(\mathrm{RR}=$ $1.08, \mathrm{IC}=0,99-1,18)$ ou 15 a 29 anos à noite em rodízio $(\mathrm{RR}=1,08, \mathrm{IC}=1,04-1,78)$. O risco foi mais aumentado naquelas mulheres que trabalharam 30 ou mais anos no plantão noturno. O teste de tendência foi estatisticamente significante $(p=0,02)$. Concluem o estudo dizendo que mulheres que trabalham em rodízio no plantão noturno pelo menos três vezes por semana, mais de dia e de tarde naquele mês, parece terem um moderado aumento no risco de câncer de mama depois de prolongados períodos de trabalho no plantão noturno.

Quando se investigou a hipótese da associação da exposição à luz a noite com aumento do risco de câncer de mama em mulheres devido à supressão da produção normal da melatonina pela glândula pineal, que pode levar ao aumento na secreção de estrogênio pelos ovários (13). Foram entrevistadas 813 pacientes com diagnóstico de câncer, com idade de 20-74 anos de idade sobre os hábitos de sono e a iluminação do quarto nos 10 anos antes do diagnóstico e a história ocupacional. O Odds Ratio (OR) e intervalo de confiança 95\% foram estimados usando a regressão logística condicional, com ajuste para outros potenciais fatores de risco. $\mathrm{O}$ resultado encontrado foi risco para câncer de mama aumentado para os sujeitos que frequentemente não dormiam a noite, quando os níveis de melatonina são mais altos $(\mathrm{OR}=$ 1,14 para cada noite por semana, IC $95 \%=$ 1,01-1,28), ou seja, com o estudo provaram a 
evidência da exposição à luz a noite pode estar associada com o risco de desenvolvimento de câncer de mama.

Em outro estudo epidemiológico (14), usando o mesmo grupo de enfermeiras acompanhadas pelo Nurses' Health Study, os autores evidenciaram a incidência de 602 casos de câncer de colo-retal entre 78586 enfermeiras acompanhadas pelo estudo. Se comparado com mulheres que nunca trabalharam a noite, as mulheres que trabalharam de 1-14 anos ou 15 anos ou mais em trabalho noturno tem um risco relativo multivariado de câncer colo-retal de 1.00. Estes dados sugerem que trabalhar três noites no mês por mais de 15 anos pode aumentar o risco de câncer colo-retal em mulheres. O resultado do estudo é compatível com a possibilidade do efeito oncogênico da exposição à luz durante a noite levando diminuição dos níveis da melatonina.

O câncer de mama é o mais freqüente nas mulheres e, que está crescendo no mundo todo, sendo associado ao estilo de vida ocidental, mas que os fatores de risco atrás desta observação não são bem conhecidos (15). A exposição à luz durante a noite, incluindo distúrbio no ritmo circadiano, mediado possivelmente pela via de síntese da melatonina e genes Clock foi sugerida como contribuintes no aparecimento do câncer de mama. A partir de um estudo de coorte realizado com enfermeiras dinamarquesas, em que o risco relativo de câncer de mama em comparação com a população feminina em geral foi de $\mathrm{RR}=1,2$, outro estudo similar foi realizado com outras trabalhadoras (exceto enfermeiras) e, os dados estão sendo avaliados, mas o autor conclui que apesar dos poucos estudos há uma sugestiva evidência de um alto risco para câncer de mama depois de trabalhar a noite.

Em estudo prospectivo (16) examinou-se a relação entre o trabalho noturno e a incidência de câncer de próstata entre 14052 trabalhadores japoneses envolvidos num grande estudo de coorte. Foi usado o mode- lo proporcional de Cox para estimar o risco, com ajuste para idade, história familiar para câncer de próstata, índice de massa corpórea, tabagismo, consumo de bebida alcoólica, tipo de trabalho, atividade física no trabalho, local de trabalho, estresse, nível educacional e estado civil. Comparando com trabalhadores diurnos, os trabalhadores noturnos em rodízio tiveram um risco significativo para o câncer de próstata $(\mathrm{RR}=3,0$, IC $95 \%=1,2$ $-7,7)$. O resultado apóia a hipótese que o trabalho noturno é um fator de risco para o câncer de próstata devido à reduzida secreção de melatonina causada pela desregulação do ritmo circadiano. Relatam que estudos demonstraram que a melatonina pode inibir a proliferação de cultura de células cancerosas de próstata.

A melatonina tem várias propriedades oncostáticas, incluindo atividade anti-estrogênica e anti-aromatase, e parece estar ligados ao metabolismo da gordura (17). O trabalhador noturno tem baixos níveis de melatonina, o que pode predispô-lo a desenvolver o câncer. O risco para o câncer endometrial é influenciado por fatores hormonal e metabólico. De um estudo de coorte com 121701 mulheres, 53487 comprovaram trabalhar a noite em rodízio em 1988 e foram acompanhadas até junho de 2004. Destas, 515 mulheres foram diagnosticadas com câncer invasivo endometrial. Foi usado o modelo de Cox para calcular o risco relativo multivariado para fatores de risco para câncer endometrial. Mulheres que trabalharam vinte anos ou mais em sistema de rodízio a noite tiveram aumento significativo no risco de câncer do endométrio (RRM=1,47; IC $95 \%=1,03-1,14)$. Em análise estratificada, mulheres obesas que trabalhavam a noite em rodízio tiveram o risco dobrado ( $\mathrm{RRM}=$ $2,09$; IC $95 \%=1,24-3,52)$ se comparadas com mulheres obesas que nunca trabalharam a noite.

Nesta categoria evidenciou-se que o trabalho noturno pode ser um fator de risco no aparecimento de câncer de mama, endome- 
trial, colo-retal e próstata, demonstrado através de estudos epidemiológicos, apesar do potencial de confundimento apontado por alguns autores, pela não definição do trabalho noturno, e foco em determinada profissão (enfermeiras).

Para discutir esta categoria, detacamos que autores (18) criticam os estudos epidemiológicos que sugerem uma um risco aumentado entre o trabalhado noturno em rodízio e câncer de mama e colo-retal (1214). pela pobre definição e quantificação das horas dos sujeitos expostos. Uma área emergente nas pesquisas é a que está focando os efeitos da dieta e do consumo de álcool no ritmo circadiano e na modificação dos efeitos da luz na ritmicidade circadiana (19).

Para o grupo de trabalho da International Agency for Research on Cancer (IARC), a partir de oito estudos epidemiológicos, mais notadamente os dois estudos de coorte realizados com enfermeiras engajadas no trabalho noturno (12-14), apesar da limitada evidência em humanos da carcinogenicidade do trabalho noturno concluíram que o trabalho noturno que envolva a desregulação do ritmo circadiano é provavelmente carcinogênico, pois a exposição á luz durante a noite desregula o ritmo circadiano, com supressão da produção da melatonina e desregulação dos genes circadianos (Per).

Baseada na classificação do IARC supracitada, um grupo de 38 mulheres dinamarquesas que desenvolveram câncer de mama depois de anos trabalhando no horário noturno conseguiram receber uma indenização da empresa de seguro. Todas estas mulheres trabalharam nos últimos 20 anos a noite e eram de baixo risco, ou seja, sem história familiar de câncer de mama e baixo consumo de álcool (20).

A maioria dos estudos que relacionam o trabalho noturno com o aparecimento do câncer tem pouca informação sobre o trabalho noturno, e falta também analisar o risco de câncer de acordo com o número cumulativo de noites trabalhadas, embora a maioria dos estudos façam com o número de anos trabalhados. Há uma limitada evidência para uma associação causal entre o trabalho noturno e o câncer de mama, enquanto é insuficiente a evidência para o câncer de próstata, cólon e câncer em geral (21).

Em estudo com mulheres norueguesas portadoras de deficiência visual notaram a baixa incidência de câncer de mama naquelas totalmente cegas, sem percepção da luz, reforçando a "melatonin hypothesis" (22), a melatonina está envolvida no ciclo menstrual e no ritmo circadiano pela alteração da secreção da gonadrotopina e prolactina e, indiretamente na secreção do estrogênio pelas gônadas. O conhecimento atual dos receptores de melatonina prova a teoria de que a inativação destes receptores pode causar câncer. As mulheres totalmente cegas não têm receptor ocular para luz, assim sendo, elas podem não ter o potencial para diminuição da produção da melatonina pela exposição à luz a noite e podem ser protegidas do câncer de mama através deste mecanismo.

Concluí-se nesta categoria que apesar dos estudos serem limitados pelo potencial de confundimento, bem como da inconsistente definição do trabalho noturno, da maioria estar focada numa profissão e a população analisada ser do Hemisfério Norte, a desregulação do ritmo circadiano pode ser um fator de risco na carcinogênese.

Assim, mais estudos prospectivos são necessários para determinar o trabalho noturno, bem como estimar quantidade de tempo segura para exposição. Apesar disto, um horário de trabalho ergonômico deve ser estabelecido para o trabalhador noturno para proteger sua saúde (18). Considerações em relação à cronobiologia são essenciais para a escolha do horário de trabalho e minimizar o potencial adverso a saúde dos trabalhadores.

\section{Efeitos da desregulação do ritmo circadiano: Trabalhador Noturno}

Nesta categoria estão os artigos que abordam 
em seu conteúdo o efeito da desregulação do ritmo circadiano na saúde do trabalhador noturno. Os tabela (4) artigos selecionados foram obtidos da base de dados Medline, de acordo com o tabela cinco (5).

A luz é o estímulo primário para a desregulação e desacerto do ritmo circadiano, que é expresso pela mudança no ritmo da melatonina (23). A produção de melatonina diminui com a exposição das pessoas a luz a noite. Desde a demonstração da potencial atividade oncostática da melatonina numa variedade de tumores, é possível que baixos níveis séricos de melatonina causada pela exposição à luz à noite aumente o desenvolvimento dos tumores em geral. Uma profunda redução da melatonina foi observada em humanos após duas semanas de exposição intermitente a luz durante a noite. Embora os níveis possam se recuperar durante o período de sono, eles não se recuperará ao nível máximo a não ser que hábitos sejam mantidos constantes, pois qualquer desregulação no ritmo circadiano irá diminuir a habilidade de recuperar-se daquela supressão. Do mesmo modo que o ritmo do sono,

Em uma análise de 4 estudos desenvolvidos em Seattle (EUA) que investigaram os efeitos dos fatores que podem desregular o ritmo circadiano e alterar a produção normal de melatonina e hormônios reprodutivos de relevância para etiologia do câncer de mama (24), observou-se que o trabalhador noturno experimenta uma série de sintomas físicos e efeitos adversos a saúde. Os mais notáveis são aqueles relacionados com a disfunção gastrointestinal, morbidade cardíaca e alguns aspectos da saúde reprodutiva (risco de aborto, prematuros e baixo peso ao nascer). Estudos epidemiológicos sugerem que mulheres que trabalham a noite, que experimentam a privação do sono, desregulação do ritmo circadiano e exposição à luz a noite tem um risco aumentado para o câncer de mama e, possivelmente ao câncer colo-retal.

Em artigo de revisão (18), evidenciou-se que o trabalho noturno desregula o ciclo vi- gília-sono, expondo o organismo humano a luz em horário biológico atípico, resultando em alterações desfavoráveis no metabolismo dos lipídios e carboidratos, resistência à insulina, na secreção ou no nível sanguíneo do hormônio do crescimento e corticosteróide. Além disso, hipertensão arterial, aumento do ventrículo esquerdo, doença coronariana, infarto do miocárdio é encontrado mais frequentemente e mais severamente em trabalhadores noturnos.

O risco de câncer de mama é alto em sociedades industrializadas e tem aumentado em países em desenvolvimento que se tornam mais ocidentalizado e as razões são pobremente conhecidas (19). Uma das possibilidades é a desregulação do ritmo circadiano devido aspectos da vida moderna, em particular o aumento do uso da luz elétrica à noite e ambiente livre do sol durante $\mathrm{o}$ dia dentro dos prédios. A desregulação do ritmo circadiano pode levar a alteração nos mecanismos de produção da melatonina e mudanças moleculares no relógio biológico localizado no núcleo supraquiasmático.

Percebe-se nesta categoria que a alteração no ritmo circadiano pela exposição à luz durante a noite pode ser um fator para várias doenças como as gástricas, cardiovascular, desordens no sono e câncer. As doenças gástricas podem ser explicadas pela mudança nos hábitos alimentares como conseqüência do horário de trabalho, além de que muitos trabalhadores aumentam seu consumo de café, álcool e consumo de drogas (estimulantes) para manterem-se acordados. Além disso, há a integração entre a regulação circadiana e a divisão celular e o processo biológico que mantém cada evento. A desregulação do ritmo circadiano pode alterar a delicada balança entre os fatores promotores e inibidores da divisão celular.

O aumento da exposição à luz durante a noite diminui o tempo viável para a produção da melatonina, reduzindo a possibilidade do efeito oncostático não específico da glândula pineal (13-23). Além disso, coloca-se a 
necessidade de mais estudos que avaliem a relação da exposição noturna á luz e o aparecimento não somente do câncer de mama, mas também de outros tipos, incluindo o risco de câncer no homem. Novos estudos devem examinar a relação entre a dieta com exposição alterada a luz, como o trabalho noturno, e focar na variação polimórfica nos genes Clock para possível associação com o risco e/ou interação com fatores que possam desregular o ritmo circadiano (19).

A razão para os problemas de saúde nos trabalhadores noturno como a insônia, problemas gástrico e cardíaco, é o conflito entre a exposição entre as horas de trabalho e o relógio biológico (25). Este último gera sinais que resultam em 24 horas de pronunciadas oscilações, como por exemplo, a temperatura retal tem a máxima (acrófase) às 17 horas e a mínima (nadir) às 5 horas da manhã. $\mathrm{A}$ melatonina tem o nível máximo aproxidamente às 4 horas da manhã e o mínimo às 16 horas da tarde.

O efeito do trabalho noturno pode manifestar-se em várias formas de doença como a úlcera péptica, câncer de mama, e apnéia do sono. A hipertensão arterial, aumento do ventrículo esquerdo, doença coronariana, e infarto do miocárdio são encontrados mais frequentemente e tendem a ser mais severos em trabalhadores noturnos do que diurnos. O exato mecanismo pelo qual o trabalho noturno causa doença cardiovascular ainda não está claramente entendido, mas acredita-se que o principal fator inclui a desregulação do ritmo circadiano e fatores de confundimento, como o fumo, hábitos alimentares, problema social que levam ao estresse, os quais são comuns entre os trabalhadores noturnos (26).

O ritmo circadiano é uma mistura de componentes exógenos e endógenos que são derivados do relógio biológico e da interação com o meio ambiente e o estilo de vida. Numerosas variáveis biológicas incluindo a temperatura corporal, o ciclo vigília-sono, desempenho psicomotor, fatores metabóli- cos e endócrinos, variação de humor e ansiedade seguem um ritmo de 24 horas. A desregulação do ritmo biológico é acompanhado de vários sintomas tanto físico como emocional. Citam associação entre o trabalho noturno e desordens gástricas, bem como bebês com baixo peso e prematuros (12).

Concluí-se nesta categoria que a desregulação do ritmo circadiano pode resultar em vários problemas de saúde para o trabalhador como doenças gástrica, cardíacas, de fertilidade, além de risco de câncer de mama em mulheres.

\section{CONSIDERAÇÕES FINAIS}

Este estudo destaca que o trabalho noturno traz inegáveis prejuízos à saúde do trabalhador, tanto no aspecto físico, quanto psíquico, emocional e social, visto que o homem tem sua vida social e ritmo orgânico ligado ao dia, ou seja, acordar pela manhã, com a luz do sol e, dormir a noite, quando o sol de põe. Os ritmos circadianos estão presentes em diversas funções corpóreas como, por exemplo: temperatura corporal, corticosteróides e eletrólitos do soro e urinários, funções cardiovasculares, secreção de enzimas gástricas, número de leucócitos do sangue, força muscular, estado de alerta, humor, memória imediata e a longo prazo.

A desregulação do ritmo circadiano pode acarretar alterações nestes mecanismos, podendo acarretar problemas de saúde no trabalhador noturno. A resistência ao câncer é frequentemente completada pelos processos imunológicos, endócrinos e antioxidantes. Estes processos podem ser alterados pela exposição a luz a noite pela supressão da produção da melatonina, que tem propriedades oncostáticas.

Foi possivel conhecer os efeitos do trabalho noturno sobre a saúde do trabalhador, advindos da desregulação do ritmo circadiano. Os sintomas podem ser físicos e emocio- 
nais, havendo desordens do aparelho digestivo, cardiovascular, endócrino, etc. Além da propriedade da melatonina, que é um hormônio com atividade oncostática e antioxidante.

O corpo possui uma lógica natural, que prepara para vigília durante o dia e o repouso durante a noite, havendo variação na produção do hormônio cortisol ao longo do dia e a produção da melatonina na presença da escuridão. A pessoa que fica acordada, ou exposta á luz durante a noite desregula o relógio biológico, forçando o organismo a alterar o seu ritmo natural, e quase sempre o trabalhador noturno não consegue inverter seus hábitos e as condições que o rodeiam para uma adaptação perfeita. $\mathrm{O}$ sono deste trabalhador fica prejudicado, pois durante o dia, além da luz do sol, o barulho da cidade atrapalha o descanso. Além disso, durante as folgas, este trabalhador tende a inverter esta rotina para resgatar sua vida social com a família e amigos.

Embora se saiba que o trabalho noturno seja prejudicial à saúde, na assistência hospitalar aos pacientes internados, esta não tem como ser suprimida. Portanto, o trabalho noturno é uma necessidade que não pode ser removida, mas temos de buscar formas para evitar ao máximo dano à saúde do trabalhador, com redução da jornada diária de trabalho, aumento do número de folgas, regulamentação de aposentadoria especial para quem faz essa jornada, além de mater um tipo especial acompanhamento médico entre outras alternativas.

$\mathrm{O}$ enfermeiro do trabalho pode contribuir com a elaboração de um esquema de trabalho em turnos que minimizem o desgaste do trabalhador, e obtendo uma melhor produtividade. A cronobiologia pode ser um eficiente instrumento para isto, pois através do estudo do cronótipo do trabalhador, aproveita-se o horário de melhor desempenho de cada indivíduo.

Assim, o conhecimento da cronobiologia pelo enfermeiro do trabalho, que é o estudo sistemático da organização temporal da matéria viva, visto que a maioria dos ciclos biológicos humanos se dá num período do dia e é diferente para cada pessoa, irá ajudá-lo a organizar o horário de trabalho, buscando aqueles mais adaptados biologicamente para o turno, de forma que a realização de escalas de serviços, lotação e/ou remanejamento dos funcionários sejam feitas de maneira que não prejudiquem a saúde do trabalhador.

Finalmente, são necessários outros estudos sobre o assunto, principalmente no Brasil, através de pesquisas de campo, visto a escassez de produção evidenciada nesta pesquisa.

\section{REFERÊNCIAS}

1. Maganhin CC, Carbonel AAF, Hatty JH, Fuchs LFP, Oliveira-Júnior IS de, Simões MJ et al. Efeitos da melatonina no sistema genital feminino: breve revisão. Rev Assoc Med Bras. 2008, 54 (3): 267-71.

2. Ferreira LL. Sono dos trabalhadores em turnos alternantes. Rev bras saúde ocup. 1985; 13(51): 25-7.

3. Paiva MB, Souza CAC, Soares E. Uma viagem pelo sono da criança internada em unidade de terapia intensiva pediátrica. R Enferm UERI. 2004; 12: 321-27.

4. Organización Mundial de la Salud. Carcinogenicity of shift-work, painting, and fire-fighting. Lyon, Francia, Lyon: International Agency for research on cancer; 2010. (Publicación científica IARC Monographs on the Evaluation of Carcinogenic Risk to Humans; 98).

5. Navara KJ, Nelson J. The dark side of light at night: physiological epidemiological and ecological consequences. Journal Pineal Research. 2007; 43: 215-24.

6. Ministério da Saúde, Instituto Nacional do Câncer. Ações de enfermagem para o controle do câncer: uma proposta de integração ensino-serviço. $3^{\mathrm{a}}$ ed. Rio de 
Janeiro, Brasil: INCA; 2008.

7. Gil AC. Como Elaborar Projetos de Pesquisa. 4a ed. São Paulo: Ed. Atlas; 2002.

8. Neves JL. Pesquisa qualitativa- Característica, usos e possibilidades. Caderno de Pesquisa em Administração. 1996; 1(3): 1-5.

9. Cervo AL. Metodologia Científica. 5a ed. São Paulo: Ed. Pearson Prentice - Hall; 2005.

10. Polit DF, Beck CT, Hungler BP. Fundamentos da pesquisa em enfermagem. $5^{\mathrm{a}}$ Ed. São Paulo: Ed.Artmed; 2004.

11. Schernhammer E, Laden F, Speizer FE, Willet WC, Hunter DJ, Kawachi I, Colditz GA. Rotating Night Shifts and Risk of Breast Cancer in Women Participating in the Nurses' Health Study. J Natl Cancer Inst. 2001; 93 (20): 1563-68.

12. Davis S, Mirick D, Stevens R. Night Shift Work, Light at Night, and Risk of Breast Cancer. J Natl Cancer Inst. 2001; 93(20): 1557-62.

13. Schernhammer E, Laden F, Speizer FE, Willet WC, Hunter DJ, Kawachi I, Fuchs CS, Colditz GA. Night-Shift Work and Risk of Colorectal Cancer in the Nurses' Health Study. J Natl Cancer Inst. 2003; 95(11): 825-28.

14. Hansen J. Risk of breast cancer after night- and shift work: current evidence and ongoing studies in Denmark. Cancer Causes Control. 2006, 17: 531-37.

15. Kubo T, Osaza K, Mikami K, Wakai K, Fujino Y, Watanabe Y et al . Prospective Cohort Study of the Risk of Prostate Cancer among Rotating-Shift Workers: Findings from the Japan Collaborative Cohort Study Am J Epidemiol. 2006; 164(6): 549-55.

16. Viswanathan A, Hankinson S, Schernhammer E. Night Shift Work and the Risk of Endometrial Cancer. Cancer Re- search. 2007; 67(21): 10618-22.

17. Haus E, Smolensky M. Biological clocks and shift work: circadian dysregulation and potential long-term effects. Cancer Causes Control. 2006; 17: 489-500.

18. Stevens RG. Artificial lighting in the industrialized world: circadian disruption and breast cancer. Cancer Causes Control. 2006; 17: 501-07.

19. Wise J. Danish night shift workers with breast cancer awarded compensation. BMJ. 2009; 338:1152.

20. Kolstad HA. Night shift work and risk of breast cancer and other cancers-a critical review of the epidemiologic evidence. Scandinavian Journal of Work, Environment and Health. 2008; 34(1): 22-5.

21. Kliukiene J, Tynes T, Andersen A. Risk of breast cancer among Norwegian women with visual impairment. Br J Cancer. 2001; 84(3): 397-99.

22. Schernhammer E, Schulmeister K. Melatonin and cancer risk: does light at night compromise physiologic cancer protection by lowering serum melatonin levels. Br J Cancer, 2004; 90: 941-43.

23. Davis S, Mirik DK. Circadian disruption, shift work and the risk of cancer: a summary of the evidence and studies in Seattle. Cancer Causes Control. 2006; 17: 539-45.

24. Åkerstedt T. Shift work and disturbed sleep/wakefulness. Occup Med. 2003; 53(2): 89-94.

25. Mosendane T, Raal FJ. Shift work and its effects on the cardiovascular system. Cardiovasc J Afr. 2008, 19(4): 210-5.

26. Xu X, Ding M, Li B, Christiani DC. Association of rotating shift work with preterm births and low birth weight among never smoking women textile workers in China. Occup Environ Med. 1994; 51(7): 470-74. 